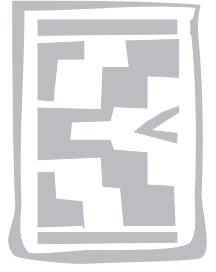

\title{
The role of the World Organisation for Animal Health (OIE) to facilitate the international trade in animals and animal products
}

\author{
G.K. BRÜCKNER \\ World Organisation for Animal Health (OIE), 12 Rue de Prony 75017, Paris, France
}

\begin{abstract}
BRÜCKNER, G.K. 2009. The role of the World Organisation for Animal Health (OIE) to facilitate the international trade in animals and animal products. Onderstepoort Journal of Veterinary Research, 76:141-146

The international trade in animals and animal products has become a sensitive issue for both developed and developing countries by posing an important risk for the international spread of animal and human pathogens whilst at the same time being an essential activity to ensure world-wide food security and food safety. The OIE has since its founding in 1924, applied a democratic and transparent decision-making process to continuously develop and review international standards for animal health and zoonoses to facilitate trade in animals and animal products. The role of the OIE is also mandated by the World Trade Organization (WTO) as international reference point for standards related to animal health. In support of its overall objective of promoting animal health world-wide, the OIE has also launched several other initiatives such as the improvement of the governance of veterinary services within its member countries and territories and to enhance the availability of diagnostic and scientific expertise on a more even global geographical distribution. Several trade facilitating concepts such as country, zonal and compartment freedom from disease as well the trade in disease free commodities has been introduced to enhance the trade in animals and animal products for all its members including those from developing and transitional countries who are still in the process of enhancing to full compliance with international sanitary standards.
\end{abstract}

\section{INTRODUCTION}

The creation of the Office International des Epizooties (OIE) as an independent inter-governmental international organisation in 1924, offered the international community well before the creation of the United Nations (OIE 2008a), a totally new and much needed international decision-making forum to guard against the regional and global spread of infectious and trade sensitive animal diseases and zoonosis. From the 28 founding countries, membership has since grown to 172 countries and territories. Known today as the World Organisation for Animal Health, the initial objectives of the OIE remain just as relevant as when it was founded. These objectives have been expanded through the years to encompass the overall objective of promoting global animal health.
In 1994, the World Trade Organization (WTO) mandated the OIE as the international reference organisation for international standards, guidelines and recommendations related to global animal health with the main purpose of facilitating international trade in terrestrial and aquatic animals and their products and to avoid the introduction of pathogens via international trade in animals and animal products, while at the same time preventing countries from setting up unjustified sanitary barriers to inhibit trade (WTO 1995).

The OIE in pursuance of this mandate has also initiated several other measures to facilitate the international trade in terrestrial and aquatic animals and their products, the most important being to assist members to identify their needs for veterinary serv- 
ice delivery to progress towards compliance with OIE international standards.

\section{THE OIE INTERNAL STANDARDS, GUIDELINES AND RECOMMENDATIONS FOR ANIMAL AND AQUATIC HEALTH}

The negotiation process between importing and exporting countries to initiate the trade in animals and animal products is usually underpinned by the mutual understanding between trade partners that trade would be accepted or allowed by the importing country if the exporting country can give acceptable sanitary guarantees to protect animal and human health in accordance with the appropriate level of sanitary protection determined and required by the importing country for importing that specific animal or animal product.

To facilitate the negotiation process and to discourage importing countries to insist on sanitary guarantees from exporting countries that would inhibit or prevent trade or to require sanitary requirements that are not scientifically justifiable, the WTO has for this very reason mandated the OIE within the Sanitary and Phytosanitary Agreement (SPS Agreement) of the WTO, as the international reference organization for setting standards for the international trade in animals and animal products.

A similar mandate was given in terms of the SPS Agreement to the Codex Alimentarius Commission (Codex) for food safety and the International Plant Protection Convention (IPPC) for matters related to plant health. Some of the key principles within the SPS Agreement are that standards set by the OIE should be science based and must be such that the main aim would be to protect animal and human health without imposing unattainable conditions for trade. Countries that are signatories to the SPS Agreement and who are also members of the OIE are obliged to honor this important requirement in trade negotiations (Brückner 2004). Countries are therefore encouraged to apply the minimum standards, guidelines and recommendations set by the OIE and wherever possible incorporate it into their national legislation. Should a standard required by an importing country be higher than that required in the OIE standards recommended for trade purposes, it must be scientifically justified and based on a risk assessment on the importing commodity (WTO 1995). OIE standards are by default already the outcome of a risk assessment and need in general not again be subjected to a risk assessment for trade purposes.
The Terrestrial Animal Health Code and the Aquatic Animal Health Code of the OIE contain the standards to be applied in the international trade in terrestrial and aquatic animals and their products. These standards are democratically adopted by the members of the OIE after been debated by specialist ad hoc groups under guidance of the OIE Specialist Commissions: the Scientific Commission for Animal Diseases, the Biological Standards Commission, the Aquatic Animal Health Standards Commission and the Terrestrial Animal Health Standards Commission. Standards are revised and updated on a continuous basis. The companion complementary volumes, the OIE Manual of Diagnostic Tests and Vaccines for Terrestrial Animals (OIE 2008b) and the similar manual for aquatic animals, specify reference techniques for diagnosing animal diseases, tests that are prescribed and recommended for trade purposes, and export certification and quality requirements for vaccines for specific animal diseases. While the focus of this paper will mainly be on animal health issues related to terrestrial animals, the same principles apply to aquatic animals.

OIE standards reflect a horizontal and a vertical dimension. The horizontal standards are described in Volume I and vertical standards in Volume II of the 2008 edition of the Code. Horizontal standards are those describing generic aspects, such as ethics in international trade or the quality of national Veterinary Services, a sine qua non condition for importing countries to trust the reliability of health certificates accompanying consignments of animals and products in cross-border trade. These certificates must be issued exclusively by the veterinary services under the full responsibility of the government of the exporting country. Other guidelines and recommendations to facilitate trade are also described in the Code such as procedures for pathogen inactivation; disposal of carcasses and dead animals; recommendations for disinfection, transport of animals by land, air or sea; identification and traceability of animals and products; requirements for border control and quarantine station; import risk analysis; equivalence; obligations and ethics in international trade; zoning and compartmentalisation; transfer of biological material and other animal welfare considerations such as slaughter of animals.

Vertical standards are those describing specific recommendations for each of the OIE listed animal diseases and zoonoses. The focus is on the animal health situation in the exporting country and assumes that either the disease is not present in the importing country or is the subject of a control or 
eradication programme. These standards specify for each disease an incubation period based on a safe risk mitigation waiting period for trade purposes; the commodities that can be traded irrespective of the disease status of a country for that specific disease; the requirements to certify a country, zone or compartment free from that disease and the risk mitigation measures than can be applied by the exporting country or required by an importing country before an animal or product is imported. General surveillance guidelines are described that could be applied for most diseases but for some diseases such as foot-and-mouth disease (FMD), highly pathogenic avian influenza and bluetongue, specific surveillance guidelines have been developed to prove absence of the circulating pathogen or to confirm claims for freedom from disease.

The OIE offers a voluntary dispute settlement mechanism for mediating trade conflicts between OIE members. This is a science-based approach for finding alternative solutions and resolving differences, as distinct from the legalistic approach used in the formal WTO system. The role of the OIE is to assist the parties to arrive at a scientifically sound conclusion.

OIE standards are developed on the basis of a highly meticulous risk analysis taking into account the fact there is no such thing as zero risk. The wealth and range of the standards published in this way enable importing countries to reduce the use of sometimes arbitrary risk analysis methods, and to favour a systematic use of OIE standards, as recommended in the SPS Agreement (WTO 1995).

\section{TRADE FACILITATING INITIATIVES BY THE OIE OTHER THAN THE PROVISION OF INTERNATIONAL STANDARDS, RECOMMENDATIONS AND GUIDELINES}

More than $70 \%$ of the 172 current members of the OIE are from developing and transitional countries. It would therefore be naïve to accept that all members of the OIE would have equal opportunities, capacity, expertise, financial means, infrastructure and level of veterinary service delivery to also equally apply these standards. The OIE also fully realizes that the disease situation varies from country to country and that for some it would be much easier to give assurances of disease freedom or absence of disease than for others. More than $70 \%$ of the current OIE listed diseases still occur for example on the African continent-either sporadically or in an endemic form while in some countries in the northern hemisphere, only five to ten of these diseases might still be present (Erlacher-Vindel, Brückner \& Vallat 2007).

\section{Evaluation of veterinary service delivery}

To assist those members who have indicated the wish to know their current level of performance in applying international standards for veterinary service delivery, the OIE has initiated a process to assess the performance of the veterinary services of countries to identify their needs in eventually moving towards compliance with OIE standards. This process known as the PVS evaluation process, applies a specific methodology where trained OIE experts visit countries wishing to be evaluated. The focus of the evaluation is on assessing performance of the country within the context of specific critical components for veterinary service delivery: human, physical and financial resources; technical authority and capability; interaction with stakeholders and access to markets. The level of advancement of a country is assessed in detail in respect of the critical competencies within each of these four components. An initial PVS evaluation is ideally followed by either a second evaluation or a more detailed gap analysis to assess the financial and other resources needed to advance within the critical competencies of each component. More than a diagnostic instrument, the OIE PVS tool promotes a culture of raising awareness and continual improvement, which can be used either passively or actively depending on the level of interest, priorities and commitment of the veterinary services and its stakeholders. In the passive mode, the OIE PVS tool helps to raise awareness and improve the understanding of all sectors including other administrations regarding the fundamental components and critical competencies the veterinary services must have in order to function effectively (OIE 2008a).

The active mode is where the maximum outcomes are realised but this mode requires a sustained commitment by both the public and private sectors. In this mode, performance is assessed, differences are explored and priorities are established, strategic actions are outlined, investments are evaluated and agreed to, and commitments made and implemented. Continuity of this process requires a true partnership between the public and the private sectors. Leadership on the part of the public sector is a fundamental and critical determinant of success.

According to G. Funes (personal communication 2008) of the current 172 members of the OIE, 80 countries have to date requested to be subjected to 
a PVS evaluation with $36(21 \%)$ from Africa representing $70 \%$ of the current 52 countries in Africa that are members of the OIE.

\section{Improvement of veterinary diagnostic capacity}

Integral to the PVS assessment process, is the identification of the need to establish scientific and technological expertise within these countries to enable them to become self-sufficient in the early detection and diagnosis of diseases and to be able to provide the scientific justification for certification of animals and animal products for trade. The OIE, realising that the majority of its 177 reference laboratories and 29 collaborating centres and expertise are located mostly in developed countries in the northern hemisphere, accepted that this ideal can only be achieved by actively moving towards scientific capacity building with the eventual aim of establishing focal points of expertise and more reference laboratories within developing countries. To enable the realisation of this ideal, the concept of twinning between laboratories was born, the aim of which is to ensure eventually an even global geographical distribution of expertise and reference laboratories allowing easier access to experts and for the rapid detection and diagnosis of disease. The principle of the twinning initiative is that an agreement is reached between a candidate laboratory in a developing country and a parent OIE reference laboratory or OIE collaborating centre for which the parent laboratory over a specified period helps the candidate laboratory to acquire the necessary expertise to eventually be able to qualify to become a designated OIE reference laboratory for a particular disease. The OIE has obtained substantial donor support to facilitate and fund this process (Erlacher-Vindel et al. 2007).

In some instances, countries, due to the lack of resources and scientific expertise, are prone to exploitation in trade related issues such as the imposing of a ban on all imports from a country that has notified an outbreak of an OIE listed disease. Such a decision taken by some members to impose a total ban on imports of animals and products without referring to the relevant provisions of the Code for these commodities is unacceptable. Though this approach is acknowledged for the few days it might take while awaiting more precise information on the animal health situation in the affected country, it should rapidly be replaced by protection measures based on OIE standards and recommendations for each of the commodities concerned. It is therefore important to acknowledge that developing and in- transition countries need a veterinary scientific community that is able to participate in the preparation of standards and to obtain the necessary expertise to challenge non-justifiable trade restrictions. To this end, the twinning concept will create the much needed opportunities to enable developing and intransition countries to become scientifically competent to debate on an equal footing the scientific justification and application of standards.

\section{The concepts of disease-free countries, zones, compartments and commodities as trade facilitating measures}

Since the early 1990s, the OIE has been given by the International Committee, composed of the delegates of the OIE member countries, the responsibility of compiling a list of member countries or zones that are officially recognised as being free from certain diseases (OIE 2008a). For this purpose, a clearly defined and impartial procedure for declaring a member country free from a disease was identified. In May 1995 a new procedure was adopted by the International Committee giving a mandate to the OIE Scientific Commission for Animal Diseases to examine in detail dossiers submitted by the delegates of member countries in support of a claim that their countries or zones within their countries could be considered free of FMD in accordance with the provisions of the Terrestrial Animal Health Code. In 1996 the first official list of OIE member countries that were FMD free without using vaccination was published after adoption by the International Committee. This process has been expanded to also include rinderpest, contagious bovine pleuropneumonia (CBPP) and bovine spongiform encephalopathy (BSE) (OIE 2008a).

However, it also became evident that country freedom due to factors such as high maintenance costs was not attainable and sustainable by all OIE members. This realisation resulted in the introduction of the concept where zones within an infected country could be officially recognised free from diseasewith or without vaccination (Brückner 2004). This process was again later refined to further facilitate trade from countries for which the achievement of neither country freedom nor zonal freedom was possible by introducing the concept of compartmentalisation. While the maintenance of either country or zonal freedom is based on maintaining separation of populations of different health status through mainly geographic entities, the concept of compartmentalisation is based on ensuring the disease free status of an establishment through the application 
of strict bio-security management practices. The concept of compartmentalisation is not a totally new concept as in certain countries in Africa and also elsewhere in the world, the principle of separating animal populations of different health status through bio-security management practices, was already applied for many years for diseases such as African swine fever and bovine tuberculosis.

The OIE fully recognises and acknowledges that advancements in science, new knowledge on the epidemiology of diseases and risk mitigation measures that can be applied to render products of animal origin safe from disease, allows for acceptance of the concept that for certain diseases and certain animal products, a specific animal product or commodity could under certain provisions be certified safe for trade purposes. This could even be applied in the event where a certain disease is present in a country but where a specific animal product does not pose a risk for transmitting that disease. The concept of safe commodity trade has therefore already been incorporated into the Code where for example milk and milk products, semen, hides and skins, gelatin and collagen from hides and skins and deboned skeletal muscle from cattle under 30 months can be traded without restriction from a country infected with BSE (OIE 2008a). The same principle is also applicable for deboned bovine meat that has undergone maturation and allowing for a lowering in $\mathrm{pH}$ below 6 to render it safe from FMD virus. Further research is needed to expand this concept as a trade facilitating measure for other OIE listed diseases. The application of this concept either on its own or in combination with either compartmentalisation or zonal freedom from disease would especially facilitate trade from those countries for which country or zonal freedom is not a sustainable option. To promote the development of this concept, the OIE will continue to encourage agrifood industries and research institutions to further the development of research programmes on unresolved issues of major importance to the development of world trade. A better knowledge for example of the conditions under which the FMD virus survives or is killed during the meat maturing process might well have a major impact on the normative provisions and the way in which OIE members apply the standards contained in the Code chapter on FMD. This is an important issue, given that more than 100 OIE members are still infected with this disease.

It would however, be naïve and irresponsible to adopt an approach based solely on the systematic inactivation of pathogens in products, which could result in members relaxing surveillance activities for animal diseases and policies on the prevention and control of potential biological disasters. The positive impact of animal health policies on poverty reduction and public health is in itself ample justification for financing and maintaining surveillance networks and rapid response mechanisms to deal with animal health threats and risks.

To guarantee the effectiveness of surveillance at the national, regional and worldwide level, a nonnegotiable pre-requisite is for all members to comply with OIE standards on the quality and evaluation of veterinary services. In addition to their surveillance mission, the veterinary services are also responsible for the reliability of the veterinary certificates they issue. These certificates accompany every consignment of animals or animal products transported in international trade globally. Compliance with OIE standards for quality of the veterinary services of a country ensures that these certificates are issued under conditions that guarantee their reliability, so that granting access to regional and global markets for all will not pose a threat to the safety of international trade.

\section{CONCLUSION}

Developing countries are increasingly coming under pressure to improve their delivery of veterinary services as a prerequisite for entering the competitive arena of international trade in animals and animal products. The demands placed on developing countries by predominantly developed countries to comply with international disease prevention standards have also resulted in increasing demands on the financial, human and technological resources of these developing countries.

The OIE in pursuance of its mandate offered in the Agreement on the Application of Sanitary and Phytosanitary Measures of the WTO and the mandate given to the OIE by its International Committee is committed to facilitate and promote as far as possible within its resources, the international trade in animals and animal products for all its members. Achieving this goal does not allow for shortcuts, will take time and demands a rational and scientific approach for future decision-making. Realising that compliance with OIE standards, guidelines and recommendations are not immediately achievable by all, the exploitation of and research into still more alternatives to facilitate trade without sacrificing the importance of good veterinary governance and the need for eventual compliance with standards, offers 
a major challenge to not only the OIE but to all international organisations seeking a more liberalized trading environment and market access for all.

\section{REFERENCES}

BRÜCKNER, G.K. 2004. Working towards compliance with international standards. Revue Scientifique et Technique, OIE, 23:95-107.

BRÜCKNER, G.K., LINNANE, S. \& DIAZ, F. 2007. Responses to a questionnaire on networking between OIE Reference Laboratories and OIE Collaborating Centres, in First International Conference of OIE Reference Laboratories and Collaborating Centres, edited by M. Lombard \& B. Dodet.
Developmental Biology, 128:77-82.

OIE 2008a. Terrestrial Animal Health Code, $17^{\text {th }}$ ed. Paris: Office International des Epizooties.

OIE 2008b. Manual of diagnostic tests and vaccines for terrestrial animals, $6^{\text {th }}$ ed. Paris: Office International des Epizooties.

ERLACHER-VINDEL, E., BRÜCKNER, G.K. \& VALLAT, B. 2007. The OIE concept of Laboratory Twinning, in First International Conference of OIE Reference Laboratories and Collaborating Centres, edited by M. Lombard \& B. Dodet. Developmental Biology, 128:119-123.

WTO 1995. The results of the Uruguay round of multilateral trade negotiations: the legal texts: agreement on the application of disease control and phytosanitary measures. Geneva: World Trade Organisation. 